\title{
Rapeseed Planting as Green Manure Improving Rice Growth and Production
}

Zhu Jifeng ${ }^{1}$, Jiang Meiyan ${ }^{1}$, Cao Liming ${ }^{1}$, Zhang Ming ${ }^{2}$, Fei Quanfeng ${ }^{3}$, Jiao Jinnan ${ }^{4}$, Zhou Xirong ${ }^{1} \Xi$, Wang Weirong ${ }^{1} \square$

1 Shanghai Academy of Agricultural Sciences, Ari-food Storage and Processing Engineering Technology Research Center of Shanghai, Shanghai, 201403, P.R. China

2 Farmer' s Training Center of Science and Technology, Fengxian District, Shanghai, P.R. China

3 Jinshan District Agro-Technology Extension Center, Shanghai, 201599, P.R. China

4 Jinshan District Agro-Science and Technology Educational Information Center, Shanghai, 201599, P.R. China

\ Corresponding author email: wangwr71@sina.com; zhouxr63@mail.sh.cn

Molecular Plant Breeding, 2021, Vol.12, No.37 doi: $10.5376 / \mathrm{mpb} .2021 .12 .0037$

Received: 03 Nov., 2021

Accepted: 12 Nov., 2021

Published: 27 Nov., 2021

Copyright (C) 2021 Zhu et al., This article was first published in Molecular Plant Breeding in Chinese, and here was authorized to translate and publish the paper in English under the terms of Creative Commons Attribution License, which permits unrestricted use, distribution, and reproduction in any medium, provided the original work is properly cited.

Preferred citation for this article:

Zhu J.F., Jiang M.Y., Cao L.M., Zhang M., Fei Q.F., Jiao J.N., Zhou X.R., and Wang W.R., 2021, Rapeseed planting as green manure improving rice growth and production, Molecular Plant Breeding, 12(37): 1-5(doi: 10.5376/mpb.2021.12.0037)

\begin{abstract}
In order to understand the effects of rapeseed planting as green manure on the growth and yield of rice cultivar 'Qing xiang ruan geng', a rapeseed cultivar 'Huyou21' were used as green manure returning to field at flowering stage. The results showed that the rice plant height and chlorophyll content increased under the treatment of rapeseed returning as green fertilizer, and also increased under $20 \%$ fertilizer reduction after rapeseed returning to field. With the amount of rapeseed returning increased, the rice yield and the yield-component traits including grains per panicle and productive panicles number increased, while the 1000-grain weight deceased, but there was no statistical difference. In addition, when the rapeseed returning amount was $22.5 \mathrm{t} / \mathrm{hm}^{2}$, the rice yield was increased significantly, and also increased under that condition with $20 \%$ fertilizer reduction.
\end{abstract}

Keywords Rice; Rapeseed return to field; Yield; Growth

The effect of applying chemical fertilizers on field ecosystems, such as soil structure destroying, fertility dropping, etc, is becoming a matter of concern in China with the extensive application of fertilizers. Green manure is a good biological fertilizer which returning to field could improve the physical and chemical nature of soil, provide natural fertilizer, increase yield and quality of latter-crops (Fu et al., 2009; Han et al., 2019). Rapeseed (Brassica napus L.) is one of the most important oil crops and it's the mainly soil improving crop as green manure (Gu et al., 2019). Research shows that rapeseed planting as green manure can increase fertilizer use efficiency and nutrient preserving capability of soil compared to Chinese vetch (Astragalus sinicus L.), which is benefit to the nutrient absorption and dry matter accumulation of latter-crop rice (Oryza sativa L.) (Gao et al., 2019; Gu et al., 2019). In addition, the glucosinolates in rapeseed were expected to be effective in suppressing harmful bacteria, spines and weeds growth, which had definite effect in overcoming the continuous cropping obstacle and increasing the resistance, yield and quality of rice (Handisenia et al., 2013; Gu et al., 2019). It is of great significance for building ecological agriculture system and raising yield when developing rapeseed planting to reduce winter bare fields.

Rice is one of the most important crops in the world, while the soil structure destroyed obviously leading to rice grew poorly with its yield and quality decreased after applying sole chemical fertilizer for long term (Chen et al, 2014). Previous studies show that green manure returning to field can improve paddy soils fertility, rice growth and yields (Xu et al., 2008; Wang et al., 2011; Chen et al., 2014). In order to understand the effects of rapeseed planting as green manure on the growth and yield of rice cultivar 'Qing xiang ruan geng', a rapeseed cultivar 'Huyou 21' were used as green manure returning to field at flowering stage. The test of green manure returning to field with fertilizer application reducing was carried out to clear the amount of rapeseed returned to provide the interest information for rapeseed planting as green manure. 


\section{Results and Analysis}

\subsection{The effect of rapeseed returning to field on rice plant height}

The plant height of rice under the stress treatment increased from rice tillering stage (July 24) to heading stage (September 4), and the increasing tendency is clear and linear. The plant heights of all rice under the stress treatment after green manure returning to field were higher than that without green manure (CK). In addition, there was little difference of plant height between the treatment of rapeseed returning to field (T2) and the same treatment with $20 \%$ fertilizer reduction (T3) (Figure 1). The result illustrated that rapeseed planting as green manure can improve plant height of rice, and there was no obviously effect on plant height under $20 \%$ fertilizer reduction after rapeseed returning to field.

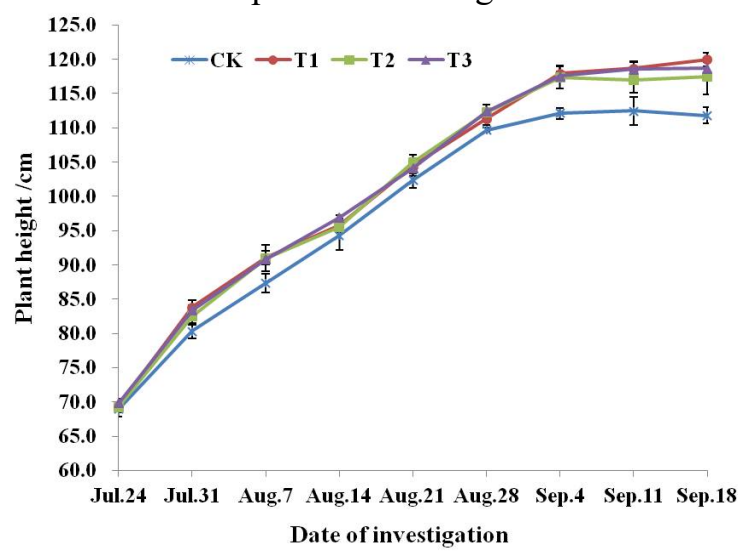

Figure 1 Effects of rapeseed manuring on rice plant height

\subsection{The effect of rapeseed returning to field on rice leaf chlorophyll content}

The leaf chlorophyll content under the stress treatment after 'Huyou21' returning to field was higher than that without green manure (CK) from rice tillering stage. And there as very significant difference of the leaf chlorophyll content between green manure returning field treatments and control at tillering stage (July 24) and booting stage (August 21), while there was no significant difference in these treatments. In short, the leaf chlorophyll content showed $\mathrm{T} 2$ ( $\mathrm{T} 3$ ) $>\mathrm{T} 1>\mathrm{CK}$ as a whole from tillering stage (July 24) to heading stage (August 28). The leaf chlorophyll content showed $\mathrm{T} 1>\mathrm{T} 2 \quad(\mathrm{~T} 3)>\mathrm{CK}$ after heading period (September 4$)$, but there was no significant difference in these treatments at rice heading stage (September 4 - September 11) (Figure 2; Table1). The results showed that the leaf chlorophyll content of rice was affected by the quantity of the rapeseed green manure returning to field at rice growth stage, and the leaf chlorophyll content improve with the increase of the green manure amount.

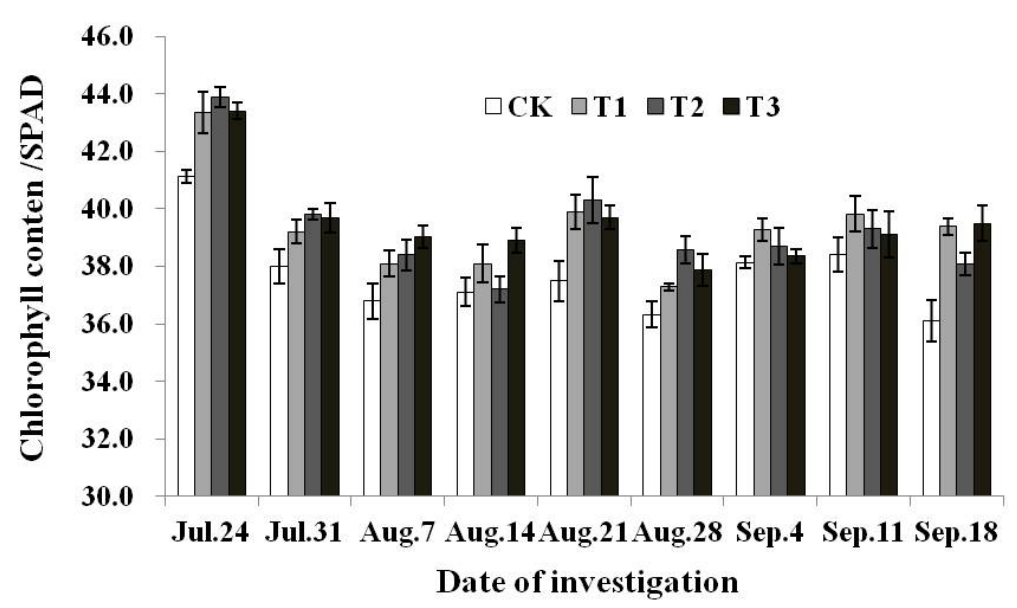

Figure 2 Effects of rapeseed manuring on rice leaf chlorophyll content after tillering 
Table 1 Comparison of rice leaf chlorophyll content under different treatments

\begin{tabular}{llllllllll}
\hline Treatment & \multicolumn{2}{l}{ Leaf chlorophyll content at different stage (SPAD) } \\
\cline { 2 - 10 } & Jul.24 & Jul.31 & Aug.7 & Aug.14 & Aug.21 & Aug.28 & Sep.4 & Sep.11 & Sep.18 \\
\hline CK & $41.1 \mathrm{a}$ & 38.0 & $36.8 \mathrm{a}$ & 37.1 & $37.5 \mathrm{a}$ & $36.3 \mathrm{a}$ & 38.1 & 38.4 & $36.1 \mathrm{a}$ \\
T1 & $43.4 \mathrm{~b}$ & 39.2 & $38.1 \mathrm{ab}$ & 38.1 & $39.9 \mathrm{~b}$ & $37.3 \mathrm{ab}$ & 39.3 & 39.8 & $39.4 \mathrm{~b}$ \\
T2 & $43.9 \mathrm{~b}$ & 39.8 & $37.2 \mathrm{a}$ & 37.2 & $40.3 \mathrm{~b}$ & $38.6 \mathrm{~b}$ & 38.7 & 39.3 & $38.1 \mathrm{~b}$ \\
T3 & $43.4 \mathrm{~b}$ & 39.7 & $38.9 \mathrm{a}$ & 38.9 & $39.7 \mathrm{~b}$ & $37.9 \mathrm{ab}$ & 38.4 & 39.1 & $39.5 \mathrm{~b}$ \\
\hline
\end{tabular}

Note: Values followed by the different letters within the same column are significantly different at $P<0.05$

\subsection{The effect of rapeseed returning to field on rice yield}

The seed-setting rate of rice was significantly different in various treatments, but there was no significant difference for other yield traits in these treatments (Table 2). And, taken as a whole, with the amount of rapeseed returning increased, the yield and the yield components (grains per panicle and productive panicles number) increased, while the 1000-grain weight deceased. From all treatments, the yield of T2 test was better than other tests. The yield of rice under T2 condition was $8360.6 \mathrm{~kg} / \mathrm{hm}^{2}$, was $5.4 \%$ higher than that of rice under control (CK). The yield of rice under T1 condition comes second, 3.3\% higher than that of CK. It indicates that the rapeseed planting as green manure can increase rice production effectively, which may be enhanced through the increased of rice grains per panicle and productive panicles number. In addition, compared to T2, the rice yield decreased $2.7 \%$ under that condition with $20 \%$ fertilizer reduction (T3), but the yield of rice under T3 still increased $2.6 \%$ than that of CK. The rice yield under T3 was $8133.1 \mathrm{~kg} / \mathrm{hm}^{2}$, which was similar to that under T1 condition $\left(8194.4 \mathrm{~kg} / \mathrm{hm}^{2}\right)$. That means when the rapeseed returning amount was $22.5 \mathrm{t} / \mathrm{hm}^{2}$, the rice yield still increased under the same condition with $20 \%$ fertilizer reduction.

Table 2 Effects of rapeseed manuring on 'Qin xiang ruan geng' yield

\begin{tabular}{lllllll}
\hline Treatment & $\begin{array}{l}\text { Panicle } \\
(\mathrm{cm})\end{array}$ & $\begin{array}{c}\text { length Grains } \\
\text { panicle }\end{array}$ & $\begin{array}{c}\text { per Seed-setting } \\
(\%)\end{array}$ & $\begin{array}{l}\text { rate } \\
(\mathrm{g})\end{array}$ & $\begin{array}{l}\text { 1000-grain weight } \\
\text { number }\left(\times 10^{6} / \mathrm{hm}^{2}\right)\end{array}$ \\
\hline CK & 11.9 & 97.8 & $95.2 \mathrm{ab}$ & 29.2 & 2.9 & 7930.9 \\
T1 & 11.4 & 102.2 & $95.9 \mathrm{a}$ & 29.0 & 3.0 & 8194.4 \\
T2 & 12.0 & 108.1 & $93.8 \mathrm{c}$ & 27.9 & 3.1 & 8360.6 \\
T3 & 12.2 & 100.9 & $94.2 \mathrm{bc}$ & 29.2 & 3.1 & 8133.1 \\
\hline
\end{tabular}

Note: Values followed by the different letters within the same column are significantly different at $P<0.05$

\section{Discussion}

Rapeseed returning to field as green manure can increase fertilizer use efficiency and nutrient preserving capability of soil, which is benefit to the nutrient absorption and dry matter accumulation of latter-crops (Gao et al., 2013; Li et al., 2019; Zhou et al., 2020). Such as Han et al. (2019) found that green manure rapeseed could significantly promote succeeding peanut mustard growth, nodules and plant dry weight. Wu et al. (2019) found the growth period of maize increased slightly with the enhancement of rape straw returning. Zhou et al. (2020) found that the amount of rapeseed returning was highly positively correlated with the succeeding rice yield and soil bacterial count. Chen et al. (2020) found that rapeseed returning to field as green manure could provide rich nutrients for rice growth and production, and also increased rice yield with less chemical fertilizers.

'Huyou21' is a leading rapeseed variety in Shanghai, it is with characters of cold tolerance and high yield, and could be planted as green manure. In this study, we found that the 'Huyou21' was returned at flowering period could increase rice yield from the year the rapeseed planted as green manure, and the rate of the succeeding rice yield increased with the returning amount, which is consistent with previous studies (Gao et al., 2013; Chen et al., 2014; Zhou et al., 2020). After 'Huyou21' returning to field, the succeeding rice plant height and the leaf chlorophyll content are improved markedly, and the grains per panicle and productive panicles number increased with the increased of rapeseed returning amount. It indicates that the rapeseed planting as green manure can increase rice production through the increased of rice grains per panicle and productive panicles number. Zhou et 
al. (2020) research showed that the suitable returning amount of 'Huyou17' was 15.0-22.5 t//hm². After 'Huyou17' returning to field, the succeeding rice yield increased as well as the effects of soil fertility and ecological conservation brought into play (Zhou et al., 2020). When the returning amount of 'Huyou21' was $22.5 \mathrm{t} / \mathrm{hm}^{2}$ with $20 \%$ fertilizer reduction, the succeeding rice yield was $2.6 \%$ higher than that of $\mathrm{CK}$. Therefore, rapeseed planting as green manure in Shanghai has great significance in reducing fertilizer and improving production of rice.

\section{Materials and Methods}

\subsection{Materials and location}

The study was performed on 2020 in Zhuanghang Experiment Station, Shanghai Academy of Agricultural Sciences. The test field was flat with medium fertility paddy soils. The physical and chemical properties of the soil were as follow: 7.5 of pH, $2.9 \%$ of organic content, $133.0 \mathrm{mg} / \mathrm{kg}$ of alkali - hydrolyzable nitrogen, $25.0 \mathrm{mg} / \mathrm{kg}$ of available phosphorus and $236.7 \mathrm{mg} / \mathrm{kg}$ of potassium in soil. The experimental rice cultivar 'Qing xiang ruan geng' was the main soft and late japonica rice with early-maturing in Shanghai. The experimental green manure cultivar was the main rapeseed 'Huyou21'. Both of them were provided by Shanghai Academy of Agricultural Sciences.

\subsection{Methods}

The full rice seed of 'Qing xiang ruan geng' from the harvest year was sown by seedling mode May $30^{\text {th }}, 2019$ and seedling on June $23^{\text {rd }}$, reaping and yield testing on October $30^{\text {th }}$. During rice growing, the BB fertilizer (375 $\mathrm{kg} / \mathrm{hm}^{2}$, NPK16-16-16) as base stage fertilizing, urea $\left(15 \mathrm{~kg} / \mathrm{hm}^{2}\right)$ as striking root fertilizer, and BB fertilizer (375 $\mathrm{kg} / \mathrm{hm}^{2}$, NPK16-16-16) as tillering fertilizer. The experiment of green manure returning to field was designed by 4 processing, including non-green manure returning to field (CK), the rapeseed returning amount was $15 \mathrm{t} / \mathrm{hm}^{2}$ (T1), the rapeseed returning amount was $22.5 \mathrm{t} / \mathrm{hm}^{2}$ (T2) and the rapeseed returning amount was $22.5 \mathrm{t} / \mathrm{hm}^{2}$ with $20 \%$ fertilizer reduction (T3). The test was studied by randomizing block arrangement with 3 repeated times. The plot area was $15 \mathrm{~m}^{2}$. Other field management measures remained consistent.

Referred to the experimental method of Wang et al. (2011), the rice plant traits were investigated through point sampling. We measured the dynamic changes of rice height from rice tillering stage (July $17^{\text {th }}, 2019$ ), where 10 plants from each plot were randomly selected to take an average. Use the SPAD-502 chlorophyll meter (Minolta Camera Co. Ltd. Japan) to measure chlorophyll content of rice sword leaf, and 30 leaves were selected to take an average. In rice mature period, 10 representative plants from each plot were selected to measure the panicle length, grains per panicle, seed-setting rate, grain weight, etc. Then the rice actual production for each plot was measured after threshing.

\subsection{Data processing and analysis}

All traits data were ordered by Excel 2010, and calculated the average values, standard deviations, coefficient of variations, etc. Variance analysis and correlation analysis of each trait were analyzed by SAS9.2 software.

\section{Authors' contributions}

Zhu Jifeng and Wang Weirong are the executors of this research. Zhu Jifeng completed the data analysis and paper writing. Zhou Xirong directed the paper modification. Wang Weirong, Jiang Meiyan, Cao Liming, Fei Quanfeng, Zhang Ming and Jiao Jinnan participated in the completion of relevant experiments. All authors read and approved the final manuscript.

\section{Acknowledgments}

This study was supported by the Shanghai Agriculture Applied Technology Development Program, China (Grant No.T20210219).

\section{References}

Chen G., Huang Y., Liu B., Liu S., Huang Y., Lin X., Liu Z., Tang Q., 2020, Effect of winter-planting rape returning with less chemical fertilizers on yield of double-cropping rice in Guangxi. Agricultural Research and Application, 33(2): 18-22

Chen H.J., Huang G.Q., Yang B.J., Wang X.W., 2014, Effects of different winter planting-green manure on the grain yield of rice and weed community of paddy field. Scientia Agricultura Sinica, 47(10): 1976-1984

Fu G.F., Wang D.Y., Xu C.M., Peng J., Han B., Tao L.X., Zhang X.F., 2009, Relationships between soil enzyme activities and rice grain yield, leaf senescence during grain filling under winter conservation tillage in paddy field, Chinese Journal of Rice Sciences 23(1): 43-50 
Gao J.S., Xu M.G., Dong C.H., Huang J., Cao W.D., Zeng X.B., Wen S.L., Nie J., 2013, Effects of long-term rice-rice-green manure cropping rotation on rice yield and soil fertility, Acta Agronomica Sinica 39(2): 343-349 https://doi.org/10.3724/SP.J.1006.2013.00343

Gu C.M., Li Y.S., Xie L.H., Hu X.J., Liao X., Qin L., 2019, Analysis on application advantages of rapeseed as green manure, Soils and Fertilizers Sciences in China, 0(1): 180-183

Han P.P., Hu X.J., Liao X.S., Xie L.H., Li Y.S., Gu C.M., Qin L., Liao X., 2019, Effects of flowering rapeseed-manure returns on soil microorganism and growth of peanut, Chinese Journal of Oil Crop Sciences 41(4): 638-642

Handisenia M., Brown J., Zemetra R., 2013, Effect of brassica ceae seed meals with different glucosinolate profiles on rhizoctonia root rot in wheat. Crop Protect, 48(48): 1-5 https://doi.org/10.1016/i.cropro.2013.01.006

Li W.G., Yang X.X., Huang C.G., Xue N.W., Xia Q., Liu X.L., Zhang X.Q., Yang S., Yang Z.P., Gao Z.Q., 2019, Effects of rapeseed green manure on soil fertility and bacterial community in dryland wheat field. Scientia Agricultura Sinica, 52(15): 2664-2677

Wang D.Y., Peng J., Xu C.M., Zhao F., Zhang X.F., 2011, Effects of rape straw manuring on soil fertility and rice growth. Chinese Journal of Rice Science, 26(1): 85-91

Wu Y.R., Wang C., Aimaierjiang A., Yang Y.C., 2019, Effects of rape straw returning and reduction of nitrogen fertilizer on the growth and yield of summer maize. Journal of Hunan Agricultural University (Natural Sciences), 46(6): 641-648

Xu M.G., Li D.C., Li J.M., Qin D.Z., Kazuyuki Y., Yasukazu H., 2008, Effects of organic manure application combined with chemical fertilizers on nutrients absorption and yield of rice in Hunan of China. Scientia Agricultura Sinica, 41(10): 3133-3139 https://doi.org/10.1016/S1671-2927(08)60171-6

Zhou D., Wu S., Chu C., Zhao Z., Wang W., 2020, Effects of rape green manure returning to field on rice yield, soil physicochemical properties and microorganism. Acta Agriculturae Shanghai, 36(5): 68-73 